\title{
Fuzzy, Integer and Fractional-order Control: Application on a Wind Turbine Benchmark Model
}

\author{
C. Viveiros ${ }^{* \ddagger}$, R. Melício ${ }^{* \dagger}$, J.M. Igreja ${ }^{\ddagger}$ and V.M.F. Mendes ${ }^{* \ddagger}$ \\ Email: \{cviveiros, jigreja ,vfmendes\}@deea.isel.ipl.pt_ruimelicio@uevora.pt \\ *Universidade de Évora, Évora, Portugal \\ †IDMEC/LAETA, Instituto Superior Técnico, Universidade de Lisboa, Lisbon, Portugal \\ $\ddagger$ ‡epartment of Electrical Engineering, Instituto Superior de Engenharia de Lisboa, Lisbon, Portugal
}

\begin{abstract}
This paper presents a comparison between proportional integral control approaches for variable speed wind turbines. Integer and fractional-order controllers are designed using linearized wind turbine model whilst fuzzy controller also takes into account system nonlinearities. These controllers operate in the full load region and the main objective is to extract maximum power from the wind turbine while ensuring the performance and reliability required to be integrated into an electric grid. The main contribution focuses on the use of fractional-order proportional integral (FOPI) controller which benefits from the introduction of one more tuning parameter, the integral fractional-order, taking advantage over integer order proportional integral (PI) controller. A comparison between proposed control approaches for the variable speed wind turbines is presented using a wind turbine benchmark model in the Matlab/Simulink environment. Results show that FOPI has improved system performance when compared with classical PI and fuzzy PI controller outperforms the integer and fractionalorder control due to its capability to deal with system nonlinearities and uncertainties.
\end{abstract}

Keywords - fractional-order control; integer order control; fuzzy controller; proportional integral; comparison; wind turbine

\section{INTRODUCTION}

Currently, the wind energy conversion system (WECS) deployment is in expansion, contributing to an increase share of converting renewable energy into electric energy. In 2012, wind power exploitation has a growth of $19.2 \%$ and this was the lowest rate achieved in more than a decade [1]. A wind energy conversion system running at variable-speed [2] offer the following advantages: mechanical stress is reduced, torque oscillations are not transmitted to the grid, and below the rated wind speed the rotor speed is controlled to achieve maximum aerodynamic efficiency. A variable-speed WECS connected to the electric grid has either a doubly fed induction generators (DFIGs) or a full-power converter. A variable-speed WECS having a DFIG [3] is implemented with the converter feeding the rotor winding and the stator winding is connected to the electric grid. The suitable use of control systems on WECS can provide for better adequacy in what regard the diminishing of losses of profit. Control systems ability to collect, analyze and process data from the wind turbine is an important issue for modern megawatt WECS. Also, the integration of a WECS into electric energy systems compels the use of control systems in order to include in the system design enough preventing to avoid performance degradation on the quality of energy injected into the electric grid. Power capturing is of extreme importance for modern megawatt WECS and a suitable control system in indispensable to lessen the losses of profit. A pitch control system is the most suitable for regulating the power capturing by the rotor due to the different positions of the blades given by the pitch angle, influencing the level of power captured. The control system for a WECS has to consider the fact that the wind turbine is driven by the wind energy which is an uncontrolled input and exhibit nonlinear dynamics. Thus, the design of a control strategy for a wind turbine [4] must consider a series of important aspects such as wind speed, the wind turbine components, the influence of the wind speed on these components and the performances that the closed loop system must have. Integer order controller is suited to deal with systems whose behavior is described by integer order differential equations. However in recent years, fractional-order control has captured the attention by the scientific community due to its capability to improve dynamic behavior of closed loop systems [5-7]. Fractional-order proportional integral controller takes advantage over integer order proportional integral controller due to the introduction of one more tuning parameter, the integral fractional-order, providing additional potential to the design specifications [8] in order to achieve a better performance. While integer and fractional-order controllers are suitable for linear systems, fuzzy controllers [9-11] can also be suitable for nonlinear systems. This paper presents a comparison between different proportional integral approaches, using a simulation study for a variable speed WECS with a control based on integer order, fractional-order and fuzzy theory. The simulations make use of the benchmark model developed by [12], using Matlab/Simulink. The rest of the paper is organized as follows: Section II describes the wind turbine benchmark; Section III presents the control strategies; Section IV presents a case study of a wind turbine benchmark and simulation results for the comparison purpose. Finally, concluding remarks are given in Section V.

\section{WIND TURBINE MODELING}

The variable speed WECS considered is a conventional horizontal axis turbine with a three-bladed rotor design and the rotor is positioned upwind of the supporting tower. The controllers have to act on the value of the pitch angle in order to maintain the output power around the rated power of the 
turbine, 4.8 MW. A more detailed description for the wind turbine benchmark model can be seen in [12].

\section{A. WECS Model}

WECS are designed in such a way as to conveniently allow for electrical energy to be attained from conversion of wind kinetic energy. Wind kinetic energy is captured by the blades receiving a twist action force which causes the blades to rotate and deliver the mechanical energy to turn the speed shafts of an electric generator. The WECS can be analyzed on a benchmark block diagram with functional systems namely: the blade and pitch system, drive train system, generator and power converter system and the controller. The block diagram of the benchmark model presented in [12] is shown in Fig. 1.

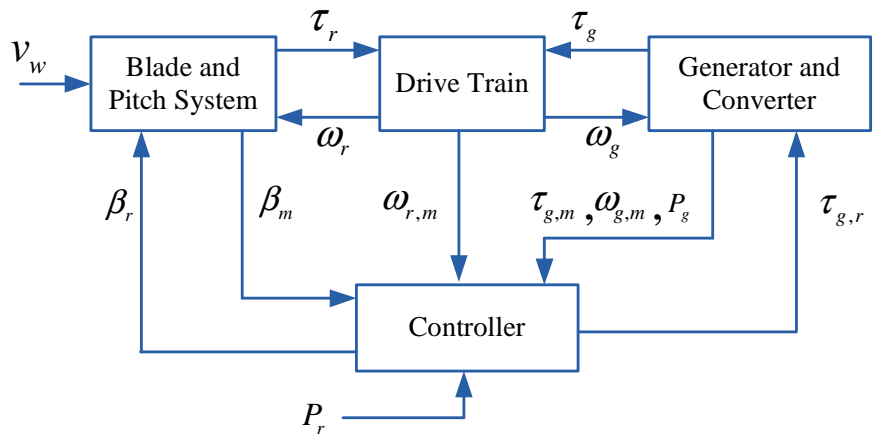

Fig. 1. Block diagram of the wind turbine benchmark [12].

In Figure 1, the variables stand for the following:

$\begin{array}{llll}v_{w}[\mathrm{~m} / \mathrm{s}] & \text { wind speed } & \tau_{r}[\mathrm{Nm}] & \text { rotor torque } \\ \tau_{g}[\mathrm{Nm}] & \text { generator torque } & \omega_{r}[\mathrm{rad} / \mathrm{s}] & \text { rotor speed } \\ \omega_{g}[\mathrm{rad} / \mathrm{s}] & \text { generator speed } & \beta\left[^{\circ}\right] & \text { pitch angle } \\ P_{g}[\mathrm{~W}] & \text { generator power } & P_{r}[\mathrm{~W}] & \text { rated power }\end{array}$

where $r, m$ subscripts designate respectively references or rotor and measurements values.

\section{A.1 Blade and Pitch System Model}

This model is a combination of the aerodynamic and pitch system model. The aerodynamics of the wind turbine is modeled in order to determine the torque acting on the blades. The aerodynamic torque is given by:

$$
\tau_{r}(t)=\sum_{j=1}^{3} \frac{\rho \pi R^{3} C_{p}(\lambda(t), \beta(t)) \nu_{w}(t)^{2}}{2}
$$

where $\rho$ is the air density, $R$ is the radius of the blades, $C_{p}$ is the power coefficient, which is a function of the pitch angle $\beta(t)$ and tip speed ratio $\lambda(t)$. The pitch system consists of three actuators that use a hydraulic mechanism to rotate the blades. The pitch actuator can be modeled as a second order system. Hence, the pitch actuator model is given by:

$$
\ddot{\beta}(t)=-2 \xi \omega_{n}(t) \dot{\beta}(t)-\omega_{n}^{2} \beta(t)+\omega_{n}^{2} \beta_{r}(t)
$$

\section{A.2 Drive Train Model}

The drive train model consists of a low-speed shaft and a high-speed shaft having inertias $J_{r}$ and $J_{g}$, and friction coefficients $B_{r}$ and $B_{g}$. The shafts are interconnected by a transmission having gear ratio $N_{g}$, combined with torsion stiffness $K_{d t}$, and torsion damping $B_{d t}$. This result in a torsion angle $\theta_{\Delta}(t)$, and a torque applied to the generator $\tau_{g}(t)$, at a speed $\omega_{g}(t)$. The linear model for the drive train is given by:

$$
\begin{gathered}
J_{r} \dot{\omega}_{r}(t)=\tau_{r}(t)+\frac{B_{d t}}{N_{g}} \omega_{g}(t)-K_{d t} \theta_{\Delta}(t)-\left(B_{d t}+B_{r}\right) \omega_{r}(t) \\
J_{g} \dot{\omega}_{g}(t)=\frac{K_{d t}}{N_{g}} \theta_{\Delta}(t)+\frac{B_{d t}}{N_{g}} \omega_{r}(t)-\left(\frac{B_{d t}}{N_{g}^{2}}+B_{g}\right) \omega_{g}(t)-\tau_{g}(t) \\
\dot{\theta}_{\Delta}(t)=\omega_{r}(t)-\frac{1}{N_{g}} \omega_{g}(t)
\end{gathered}
$$

\section{A.3 Generator and Power Converter Model}

The power converter dynamics is modeled by a first order system where $\alpha_{g c}$ is the inverse of the first order time constant and $\tau_{g, r}$ is the reference torque to the generator. This model is given by:

$$
\dot{\tau}_{g}(t)=-\alpha_{g c} \tau_{g}(t)+\alpha_{g c} \tau_{g, r}(t)
$$

the power produced by the generator is given by:

$$
P_{g}(t)=\eta_{g} \omega_{g}(t) \tau_{g}(t)
$$

where $\eta_{g}$ denotes the efficiency of the generator.

\section{CONTROL STRATEGIES}

The design of a control strategy for a wind turbine must consider a series of important aspects such as wind speed, the wind turbine components, the influence of the wind speed on these components and the performances that the closed loop system must have. It also has to take into account the fact that the energy conversion system is disturbed by the turbulent component of the wind speed. The pitch angle and the tip speed ratio are important values to conveniently achieve the objective of the control. The tip speed ratio is given by:

$$
\lambda(t)=\frac{\omega_{r}(t) R}{v_{w}(t)}
$$

where $\omega_{r}(t)$ is the angular rotor speed. With a particular pitch angle, the optimal choice of the tip speed ratio allows a conversion at the maximum power permissible with that angle. A broadly review of the literature on wind turbine control gives as a conclusion that the maximization of the power associated with the energy conversion occurs when the wind speed is in the range between the cut-in and the cut-out wind speed. Four regions of operation of a wind turbine can be distinguished as shown in Fig. 2, where $v_{\min }$ and $v_{\max }$ are respectively the cut-in and cut-out wind speeds. Region I correspond to the start up of the turbine. Region II corresponds 
to power optimization conditions, in a wind speed range that enables the conversion at global optimum rating within safety conditions. The control objective in this region is to capture all possible wind power with a pitch angle equal to 0 degrees, attaining global maximum power. Region III corresponds to a conversion at constant power due to the fact that the wind has more power than the one that is possible to convert, ensuring that the wind turbine works within its limits. The control objective in this region is to operate the wind turbine at the nominal power. Finally, region IV corresponds to high wind speed thus leading to the shutdown of the wind turbine in order to prevent damages.

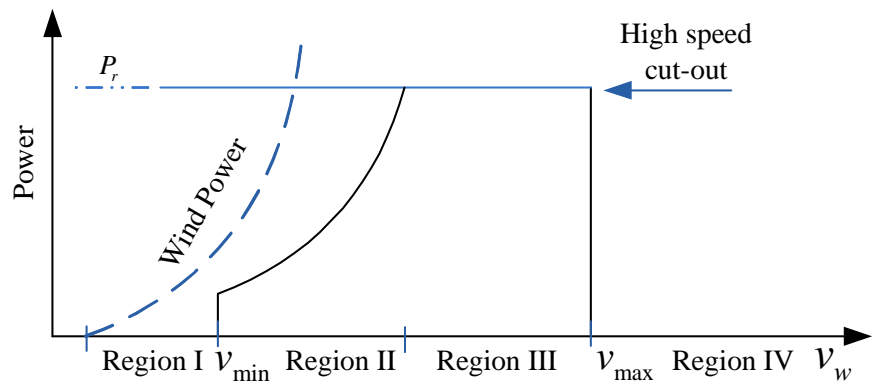

Fig. 2. Regions of power by wind speed [13].

In this paper, only regions II and III are considered. For both regions, the proposed controllers provide pitch angle reference, $\beta_{r}(k)$ and generator torque reference, $\tau_{g, r}(k)$. In region II, power optimization, it is considered $\beta_{r}(k)=0^{\circ}$ for the pitch reference and for the generator torque reference the following equations:

$$
\tau_{g, r}(k)=K_{o p t}\left(\frac{\omega_{g}(k)}{N_{g}}\right)^{2}
$$

and

$$
K_{\text {opt }}=\frac{1}{2} \rho A R^{3} \frac{C p_{\max }}{\lambda_{o p t}^{3}}
$$

where $A$ is the area covered by the blades and $\lambda_{\text {opt }}$ is found as the optimum point in the power coefficient. In region III the pitch reference is given by the different proportional integral approaches, equations (12), (17), (19) and generator torque reference is given by:

$$
\tau_{g, r}(k)=\frac{P_{r}(k)}{\eta_{g} \omega_{g}(k)}
$$

\section{A. Integer Order Controller}

The PI control action is defined by:

$$
\begin{aligned}
& u(k)=u(k-1)+k_{p} e(k)+\left(k_{i} T_{s}-k_{p}\right) e(k-1) \\
& e(k)=\omega_{g}(k)-\omega_{\text {nom }}(k)
\end{aligned}
$$

where $\omega_{\text {nom }}(k)$ is the nominal turbine speed and $u(k)=\beta_{r}(k)$.

\section{B. Fractional-order Controller}

The fractional-order differentiator can be denoted by a general operator ${ }_{a} D_{t}^{\mu}[14,15]$, given by:

$$
{ }_{a} D_{t}^{\mu}=\left\{\begin{array}{cc}
\frac{d^{\mu}}{d t^{\mu}}, & \Re(\mu)>0 \\
1, & \Re(\mu)=0 \\
\int_{a}^{t}(d \tau)^{-\mu}, & \Re(\mu)<0
\end{array}\right.
$$

The mathematical definition of fractional derivatives and integrals has been the subject of several approaches. The most frequently encountered definition is called Riemann-Liouville definition, in which the fractional-order integrals [15] are defined as:

$$
{ }_{a} D_{t}^{-\mu} f(t)=\frac{1}{\Gamma(\mu)} \int_{a}^{t} \frac{f(\tau)}{(t-\tau)^{1-\mu}} d \tau
$$

where

$$
\Gamma(x) \equiv \int_{0}^{\infty} y^{x-1} e^{-y} d y
$$

is the Euler's Gamma function, $a$ and $t$ are the limits of the operation, and $\mu$ is the integral fractional-order which can be a complex number. In this paper, $\mu$ is assumed as a real number satisfying $0<\mu<1$. Also, $a$ is taken as a null value and the following convention is used: ${ }_{0} D_{t}^{-\mu} \equiv D_{t}^{-\mu}$. The differential equation in time domain [15] of the fractional-order $P I^{\mu}$ controller is given by:

$$
u(t)=K_{p} e(t)+K_{i} D_{t}^{-\mu} e(t)
$$

where $K_{p}$ is the proportional constant and $K_{i}$ is the integral constant. Using the Laplace transform on fractional calculus [15], the transfer function of the fractional-order $P I^{\mu}$ controller is given by:

$$
G(s)=K_{p}+K_{i} s^{-\mu}
$$

\section{Fuzzy Proportional Integral}

The fuzzy PI controller structure [16] takes into account two inputs, the control error, $e(k)$, change in error, $\Delta e(k)$ and one output, control action $u(k)$ and it can be seen in Fig. 3.

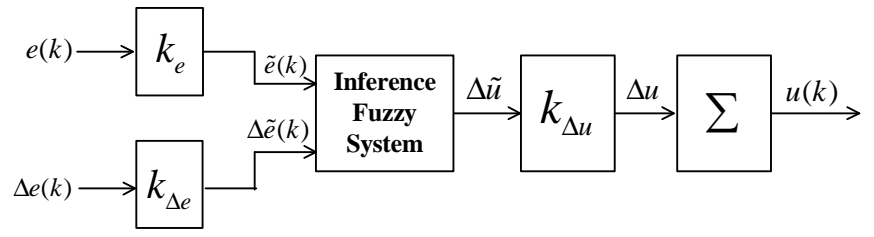

Fig. 3. Fuzzy PI controller structure.

Table I summarizes the rule base format, i.e., Mamdani-type inference is the fuzzy inference considered in this paper. Forty-nine rules were used in this controller. Seven fuzzy sets were used both for $\tilde{e}$ and $\Delta \tilde{e}$, namely, $\{\mathrm{NB} ; \mathrm{NM}$;NS;ZE; PS;PM;PB \} where: NB, Negative Big; NM, Negative 
Medium; NS, Negative Small; ZE, Zero; PS, Positive Small; PM, Positive Medium; PB, Positive Big.

TABLE I. RULE BASE FORMAT

\begin{tabular}{|c|c|c|c|c|c|c|c|}
\hline$\tilde{e}, \Delta \tilde{e}$ & NB & NM & NS & ZE & PS & $\mathrm{PM}$ & PB \\
\hline NB & \multirow{2}{*}{\multicolumn{3}{|c|}{ NB }} & NB & $\mathrm{NM}$ & NS & ZE \\
\hline NM & & & & NM & NS & ZE & PS \\
\hline NS & NB & NB & NM & NS & ZE & PS & PM \\
\hline ZE & NB & NM & NS & ZE & PS & $\mathrm{PM}$ & PB \\
\hline PS & NM & NS & ZE & PS & $\mathrm{PM}$ & PB & PB \\
\hline $\mathrm{PM}$ & NP & ZE & PS & PM & & \multirow{2}{*}{\multicolumn{2}{|c|}{ PB }} \\
\hline PB & ZE & PS & PM & PB & & & \\
\hline
\end{tabular}

The fuzzy PI control action equation is given by

$$
\begin{aligned}
& u(k)=u(k-1)+k_{\Delta u} f_{N L}\left(e(k), k_{e}, \Delta e(k), k_{\Delta e}\right) \\
& e(k)=r(k)-y(k)
\end{aligned}
$$

where $r(k)$ is the reference, $y(k)$ is the system output, $f_{N L}$ is a non linear function representing the inference fuzzy system and scaling factors are $k_{e}, k_{\Delta e}, k_{\Delta u}$.

\section{SimUlATION AND RESUlts}

The simulation was performed using Matlab/Simulink environment. The wind turbine benchmark is linearized for a power set-point, $P_{r}$, of $4.8 \mathrm{MW}$ and a wind speed, $v_{w}$, of $13 \mathrm{~m} / \mathrm{s}$. The wind turbine parameters are given by: $R=57.5 \mathrm{~m}, \rho=1.225, \xi=0.6, \omega_{n}=11.11, \alpha_{g c}=50$, $\eta_{g}=0.98, \omega_{\text {nom }}=162[\mathrm{rad} / \mathrm{s}]$. The parameters for integer and fractional proportional integral controller [12] are $K_{P}=4$, $K_{I}=1, \mu=0.5$ and sampling time $T s=0.01 \mathrm{~s}$. White noise is added to the wind speed sequence in order to simulate a wind disturbance. This noise is shown in Fig. 4.

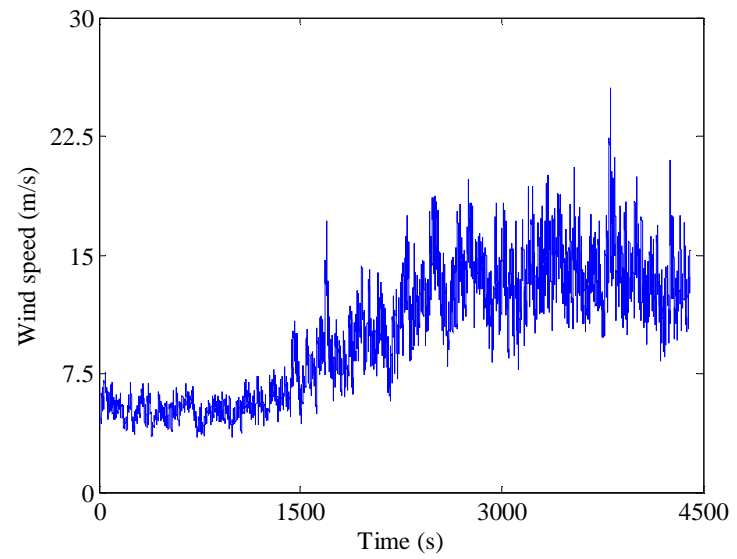

Fig. 4. Wind speed with noise.

All control strategies should have the control mode switching from region II to region III if $P_{g}(k)>P_{r}(k)$ or $\omega_{g}(k)>\omega_{\text {nom }}(k)[\mathrm{rad} / \mathrm{s}]$ and switching back from region III to region II if $\omega_{g}(k)<\omega_{\text {nom }}(k)-\omega_{\Delta}$. Where $\omega_{\Delta}$ is a small offset used to prevent several switches between control modes.

\section{A. Integer Order Proportional Integral}

The integer order PI controller structure implemented in Matlab/Simulink is shown in Fig. 5.

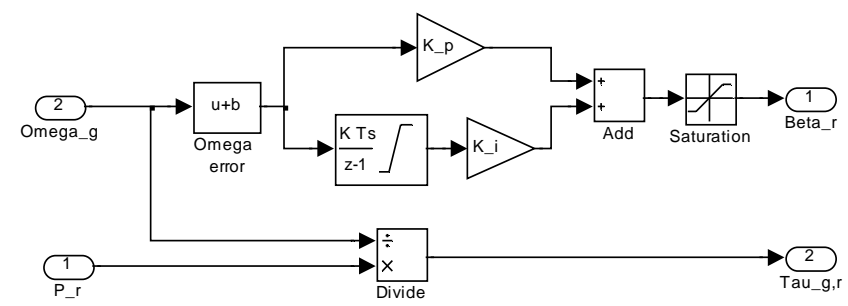

Fig. 5. Integer order PI controller structure.

The electric power at the generator follows the reference power with some peaks due to the wind disturbance as shown in Fig. 6.

The pitch angle variation is shown in Fig. 7. It can be seen that the pitch angle varies around 22 degrees with some peaks above 30 degrees.

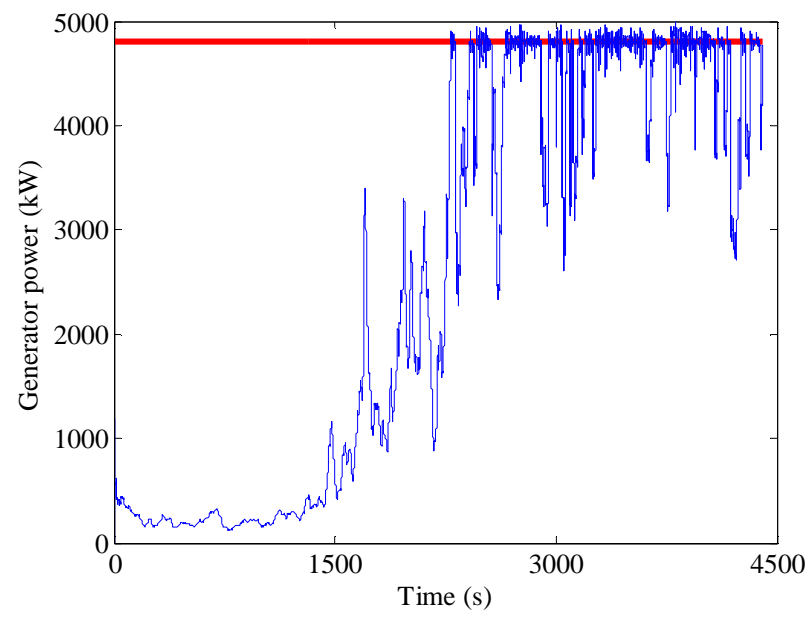

Fig. 6. Generator power with PI controller and reference power.

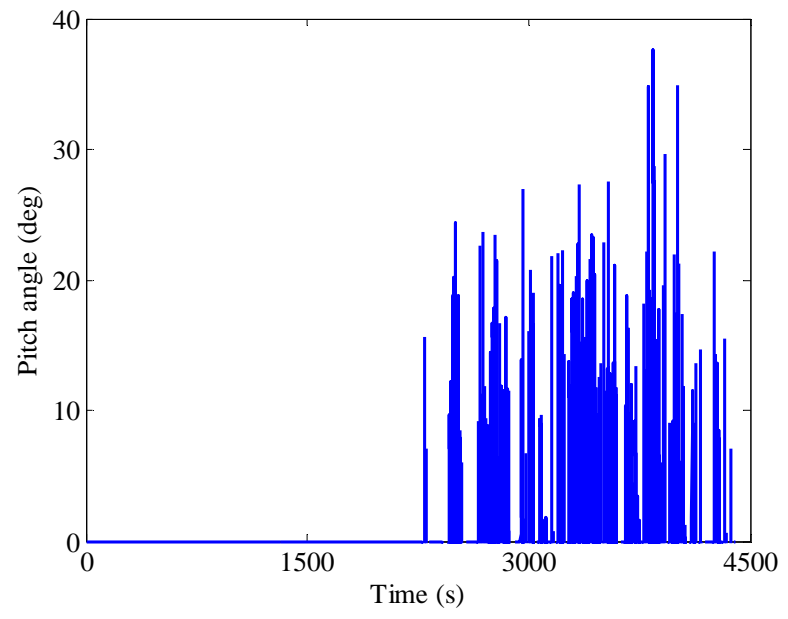

Fig. 7. PI controller pitch angle. 


\section{B. Fractional-order Controller}

The fractional-order PI controller structure implemented in Matlab/Simulink is shown in Fig. 8. The digital fractional-order integrator was based on power series expansion of the trapezoidal (Tustin) rule [17] and the discrete $P I^{\mu}$ control parameters were obtained using a Matlab function [18].

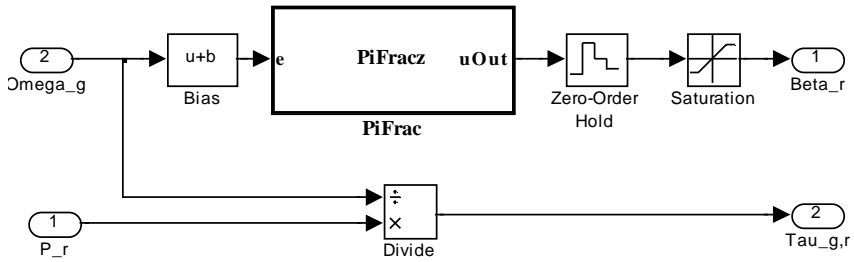

Fig. 8. Fractional-order PI controller structure.

The electric power and reference power at the generator are shown in Fig. 9. The electric power exhibits a similar response as the one with an integer order PI controller.

In Fig. 10 the pitch angle varies around 20 degrees, with just one value above 30 degrees. From the control point of view less effort is needed when compared to integer order.

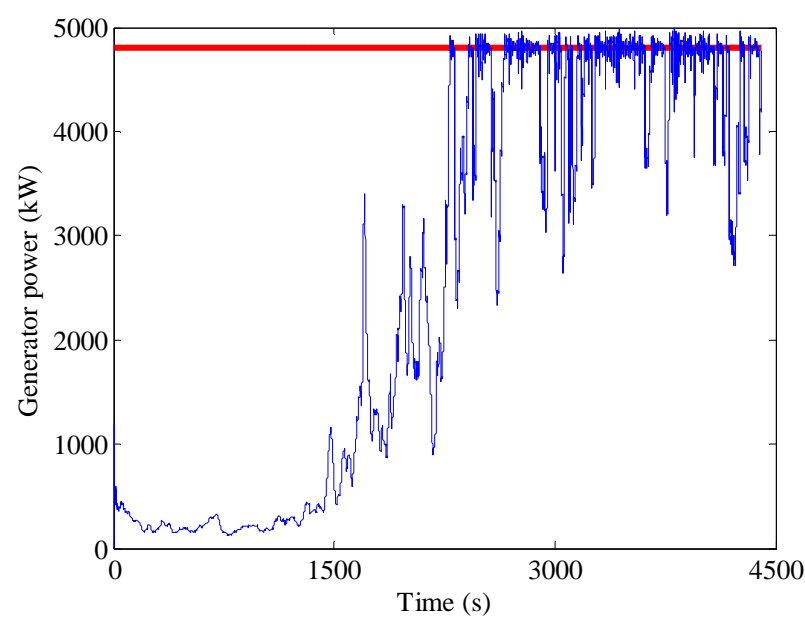

Fig. 9. Generator power with FOPI controller and reference power.

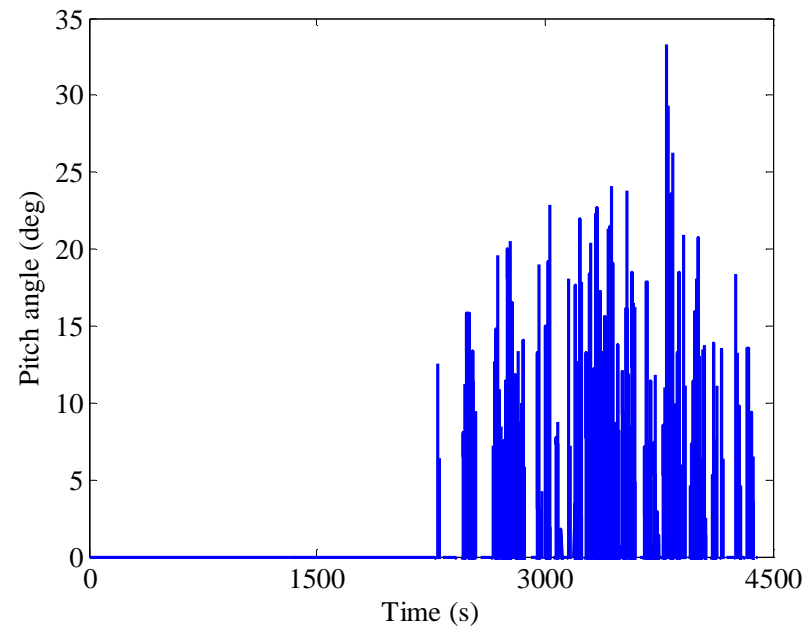

Fig. 10. FOPI controller pitch angle.

\section{Fuzzy Proportional Integral}

The Fuzzy PI controller structure implemented in Matlab/Simulink is shown in Fig. 11. The $f_{N L}$, non linear function, is represented by fuzzy logic controller and scaling factors were obtained through trial and error being the following: $k_{e}=0.4 ; k_{\Delta e}=0.5$ and $k_{\Delta u}=1.5$.

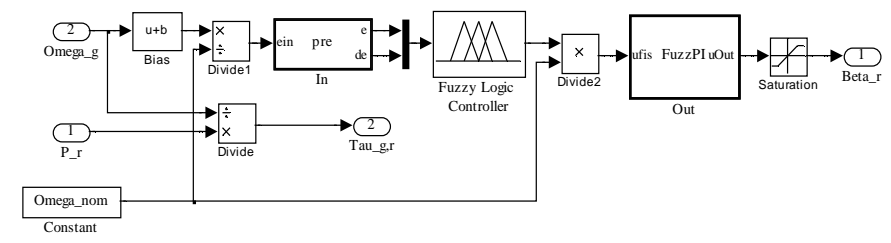

Fig. 11. Fuzzy PI controller structure.

The electric power follows the reference electric power with some peaks but presents a smoother response with few oscillations around reference power. The electric generator power and reference power are shown in Fig. 12. The pitch angle variation is shown in Fig. 13. The pitch angle varies around 24 degrees and the maximum angle achieved is 30 degrees.

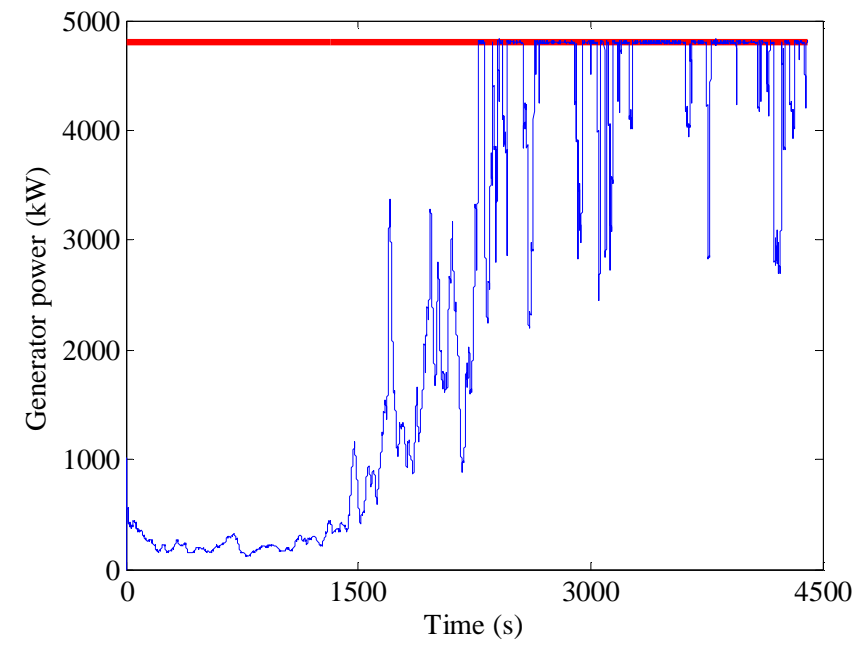

Fig. 12. Generator power with Fuzzy PI controller and reference power.

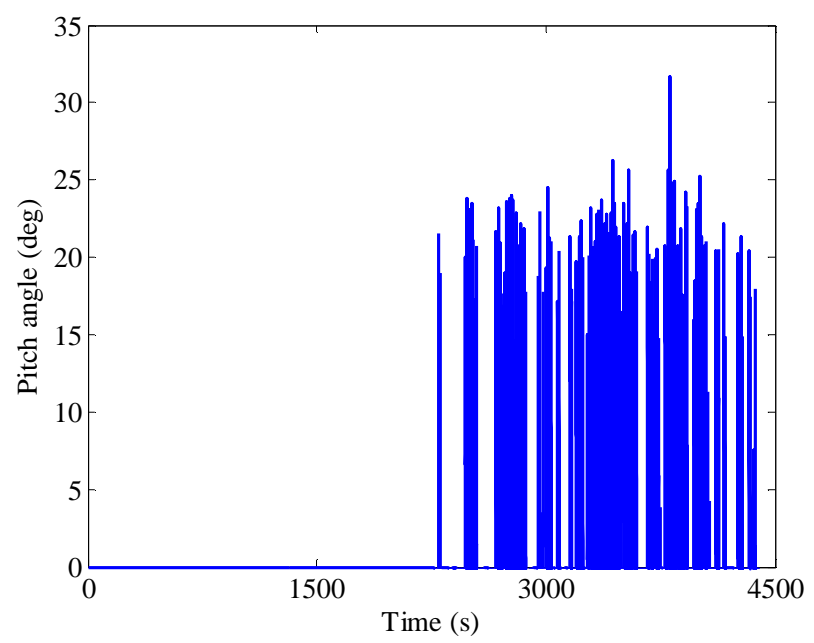

Fig. 13. Fuzzy PI controller pitch angle. 


\section{Controllers Performance Assessment}

In order to evaluate the performance of the controllers the following metric were applied:

1) the integral of time multiplied by the absolute value of the error (ITAE):

$$
\operatorname{ITAE}=\int_{0}^{t_{f}} t \cdot|e(t)| d t
$$

2) integral of the square value (ISV) of the control input:

$$
I S V=\int_{0}^{t_{f}} u^{2}(t) d t
$$

where ITAE is used as numerical measure of tracking performance for the entire error curve and ISV shows the energy consumption. In table II is summarized the performance assessment results.

TABLE II. PERFORMANCE ASSESSMENT

\begin{tabular}{|l|c|c|c|}
\hline & $\begin{array}{c}\text { Integer order } \\
\text { PI }\end{array}$ & $\begin{array}{c}\text { Fractional-order } \\
\boldsymbol{P I}\end{array}$ & Fuzzy $\boldsymbol{P I}$ \\
\hline ITAE & $1.210 \times 10^{15}$ & $1.207 \times 10^{15}$ & $1.16 \times 10^{15}$ \\
\hline ISV & $6.05 \times 10^{6}$ & $5.78 \times 10^{6}$ & $6.16 \times 10^{6}$ \\
\hline
\end{tabular}

\section{CONCLUSIONS}

In this paper it was presented a comparison between proportional integral control approaches for variable speed wind turbines. A wind energy conversion system (WECS) running at variable-speed offers many advantages such as: mechanical stress is reduced, torque oscillations are not transmitted to the grid, and below the rated wind speed the rotor speed is controlled to achieve maximum aerodynamic efficiency.

Integer and fractional-order controllers were designed using linearized wind turbine model whilst fuzzy controller was designed taking into account system nonlinearities. These controllers operated in the full load region and the main objective was to capture maximum power generation while ensuring the performance and reliability required for a wind turbine to be integrated into an electric grid.

Fractional-order proportional integral (FOPI) controller benefited from the introduction of one more tuning parameter, the integral fractional-order, thus presenting an advantage over integer order proportional integral (PI) controller.

A comparison between proposed control approaches for the variable speed wind turbines was presented using a wind turbine benchmark model in the Matlab/Simulink environment.

Results showed that FOPI has improved system performance, regarding system error and system control effort, when compared with classical PI. Fuzzy PI controller outperforms the integer and fractional-order control in the system overall response due to its capability to deal with system nonlinearities and uncertainties, but at the expense of a higher control effort.

\section{ACKNOWLEDGMENT}

This work was partially supported by Fundação para a Ciência e a Tecnologia, through IDMEC/LAETA, Instituto Superior Técnico, Universidade de Lisboa, Lisbon, Portugal.

\section{REFERENCES}

[1] G. Gsänger, and J.-D. Pitteloud, “World Wind Energy Report 2012,” in Proc. 12th World Wind Energy Conference \& Renewable Energy Exhibition, Havana, Cuba, 2013, pp. 1-19.

[2] M. Garcia-Sanz, and C.H. Houpis, Wind Energy Systems: Control Engineering Design, CRC Press, Taylor \& Francis, Boca Raton, 2012.

[3] R. Melício, and V.M.F. Mendes, "Doubly fed induction generator systems for variable speed wind turbine," in Proc. 9th SpanishPortuguese Congress on Electrical Engineering-9CHLIE, Marbella, Spain, 2005, pp. 161-164.

[4] F. Bianchi, H. Battista, and R. Mantz, Wind turbine control systems. London, UK, Springer-Verlag, 2007.

[5] Y. Q. Chen, "Ubiquitous fractional-order controls?," in Proc. 2nd IFAC Fraction. Differentiation Appl., Porto, Portugal, 2006, pp. 1-12.

[6] R. Caponetto, G. Dongola, L. Fortuna, and I. Petráš, Fractional-order systems: modeling and control applications, Singapore, World Scientific Publishing, 2010.

[7] I. Petráš, Fractional-Order Nonlinear Systems: Modeling, Analysis and Simulation, HEP, Springer, Series: Nonlinear Physical Science, 2011.

[8] C. A. Monje, B. M. Vinagre, V. Feliu, Y. Q. Chen, "Tuning and Autotuning of fractional-order controllers for Industry Applications," Control Engineering Practice, Vol. 16, pp 798-812, 2008.

[9] A. Macedo, and W. Mota, "Wind turbine pitch angle control using fuzzy logic,” in Proc. IEEE Transm. Distrib. Conf. Exp. Latin America-2012, Montevideo, Uruguay, 2012, pp. 1-6.

[10] F. Scherillo, L. Izzo, D. Coiro, and D. Lauria, "Fuzzy logic control for a small pitch controlled wind turbine," in Proc. Intern. Symp. Power Electron. Eletric. Drives Autom. Motion-SPEEDAM 2012, Naples, Italy, 2012, pp. 588-593.

[11] L.A. Torres-Salomao, and H. Gamez-Cuatzin, "Fuzzy logic control and PI control comparison for a 1.5 MW horizontal axis wind turbine," in Proc. 16th Intern. Conf. Syst. Theory, Control and Comput.-ICSTCC, Sinaia, Romania, 2012, pp. 1-6.

[12] P.F. Odgaard, J. Stroustrup, and M. Kinnaert, "Fault tolerant control of wind turbines: a benchmark model,” IEEE Trans. Control Systems Technology, vol. 12, pp. 1168-1182, July 2013.

[13] K.E. Johnson, L.Y. Pao, M.J. Balas, and L.J. Fingersh, "Control of variable-speed wind turbines: standard and adaptive techniques for maximizing energy capture,” IEEE Control Systems, vol. 26, pp. 70-81, June 2006.

[14] M. Seixas, R. Melício, and V.M.F. Mendes, "Offshore wind turbine simulation: multibody drive train. Back-to-back NPC (neutral point clamped) converters. Fractional-order control," Energy, vol. 69, pp. 357-369, 2014.

[15] I. Podlubny, Fractional differential equations. San Diego, Academic Press, 1999.

[16] D. Driankov, H. Hellendoorn, and M. Reinfrank, An introduction to fuzzy control. 2nd Ed. Berlin. Springer-Verlag, 1996.

[17] Y. Q Chen, I. Petráš, and D. Xue. Fractional-order control-A tutorial, in Proc. of the American Control Conference, St. Louis, USA, 2009, pp. 1397-1411.

[18] I. Petráš, Discrete Fractional-order PID Controller, MathWorks, Inc Matlab Central File Exchange, URL: http://www.mathworks.com/matlabcentral/fileexchange/33761, 2011 